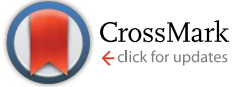

Cite this: RSC Adv., 2017, 7, 5412

Received 13th November 2016 Accepted 19th December 2016

DOI: $10.1039 / c 6 r a 26722 j$

www.rsc.org/advances

\section{Efficient esterification of $n$-butanol with acetic acid catalyzed by the Brönsted acidic ionic liquids: influence of acidity $\dagger$}

\begin{abstract}
Jignesh Lunagariya, ${ }^{a}$ Abhishek Dhar ${ }^{b}$ and Rohit L. Vekariya*c
The efficiency in the catalytic performance of halogen free functionalized room-temperature Brönsted acidic ionic liquids (BAILs), having different acidities (due to the ILs containing zero, a single, and or a double $-\mathrm{SO}_{3} \mathrm{H}$ functional group), for the esterification of $n$-butanol with acetic acid under various reaction conditions was investigated. The synthesized BAILs have much weaker corrosiveness than that $\mathrm{of}_{2} \mathrm{SO}_{4}$. The nature of both counter anion and cation as well as the presence of additional functional $\left(-\mathrm{SO}_{3} \mathrm{H}\right)$ groups influenced the behavior of the catalyst. Interestingly, the acidic character of the ILs facilitates the reaction under extremely mild conditions, with a short reaction time, and reduction in the side reactions; moreover, the liquid-liquid biphasic reaction mode leads to good yields. The physicochemical properties of these BAILs were characterized by a variety of different analytical and spectroscopic techniques, such as NMR, FT-IR, mass spectrometry, TGA, and UV-vis spectroscopy for the determination of Hammett acidity. In particular, IL-5 having the highest acidity demonstrated excellent catalytic activity for esterification. An additional advantage of BAILs is the simple procedure for the separation of product and catalyst, where the catalysts can be easily recycled without the loss of catalytic activities, making IL-5 an important alternative catalyst for a commercially viable esterification process.
\end{abstract}

\section{Introduction}

Acetates are a type of fine chemicals that play a crucial role in the modern chemical industry such as flavorings in food industry, for solvent extraction in pharmaceutical industry, textile industry, etc. Esterification of alcohols with carboxylic acids is one of the most important reactions in organic synthesis. ${ }^{1}$ However, esterification is an equilibrium reaction and generally requires removal of water for satisfactory yield. ${ }^{2}$ As a most familiar catalyst, $\mathrm{H}_{2} \mathrm{SO}_{4}$ could give high yield; however, it is strongly corrosive, making this process environmentally problematic. One of the most promising areas of research in the new "green" technologies is the application of ionic liquids (ILs), ${ }^{3-7}$ which is mainly due to their specific properties, such as low vapor pressure, non-volatile nature, nonflammability, Brönsted and Lewis acidity, and in some cases, their super acidity. ${ }^{8-16}$ Reactions in IL are one of the interesting research topics, and many reactions having ILs as either reaction media or catalysts have been witnessed. ${ }^{17,18}$

\footnotetext{
${ }^{a}$ Department of Chemistry, College of Chemistry and Materials Science, Jinan University, Guangzhou 510632, PR China

${ }^{b}$ Department of Chemical Technology, University of Calcutta, 92, Acharya Prafulla Chandra Road, Kolkata 700 009, India

${ }^{c}$ School of Chemical Engineering, Fuzhou University, Fuzhou 350116, Fujian Province, PR China. E-mail: rohit.vekariya@yahoo.com

† Electronic supplementary information (ESI) available. See DOI: 10.1039/c6ra26722j
}

The esterification of alcohols with carboxylic acids in acidic chloroaluminate IL was investigated by Deng et al. ${ }^{19}$ Moreover, the esterification of alcohols with acid anhydrides in the presence of basic or acidic catalysts, such as 4-pyrrolidinopyridine and $\mathrm{H}_{2} \mathrm{SO}_{4}$, has been previously reported. ${ }^{20,21}$ Lee et $a .^{22}$ employed the metallic Lewis acids, such as $\mathrm{Cu}(\mathrm{OTf})_{2}, \mathrm{Sc}(\mathrm{OTf})_{3}$, $\mathrm{Yb}(\mathrm{OTf})_{3}$, and $\operatorname{In}(\mathrm{OTf})_{3}$, as catalysts in ILs to catalyze the esterification of alcohols with acetic anhydride. However, these catalysts suffer from some limitations such as long reaction time, low conversion rate, and lower yield. Moreover, metal triflates were rather expensive and their recovery was a significant challenge. Duan et al. ${ }^{23}$ employed the neutral IL, [Bmim] $\mathrm{BF}_{4}$, to promote the esterification of tertiary alcohols with acetic anhydride. However, the time of reaction was long and the yields of the esterification of primary alcohols with acetic anhydride in $[\mathrm{Bmim}] \mathrm{BF}_{4}$ were not satisfactory. Cole et al. ${ }^{17}$ reported a new approach for esterification using BAILs, such as 3butyl-1-(3-sulfopropyl/butyl)-1 $H$-imidazolium sulfonic acid based ILs, as dual solvent-catalysts, whereas Zhu et $a .^{24}$ demonstrated 1-methylimidazolium tetrafluoroborate, ([Hmim] $\mathrm{BF}_{4}$ ), as a green catalyst and recyclable medium for esterification. Gui et al. ${ }^{25}$ reported that BAILs such as 1-(4-sulfonic acid) butyl-3-methylimidazolium hydrogen sulfate, 1-(4-sulfonic acid) butylpyridinium hydrogen sulfate, and $\mathrm{N}$-(4-sulfonic acid) butyl triethylammonium hydrogen sulfate were also efficient catalysts for esterification. Although the abovementioned catalytic systems (e.g., $\left.[\mathrm{Hmim}] \mathrm{BF}_{4}\right)$ display satisfactory conversion rates 


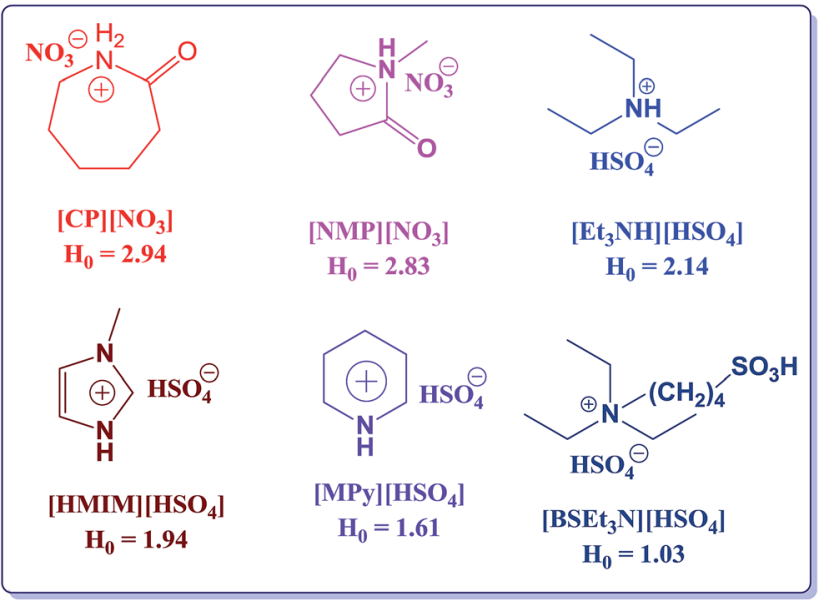

Scheme 1 Examples of various structures of BAILs and their respective acidities. ${ }^{31,32}$ and selectivity for esterification, a large quantity of IL is often required. Using an example of a particular alcohol and acid, $n$ butyl acetate is mainly produced by the acid-catalyzed esterification reaction of $n$-butanol with acetic acid. ${ }^{26}$ The conventional industrial production of $n$-butyl acetate is carried out in a batch process using mineral acids (e.g., sulfuric acid, $p$-toluenesulfonic acid) as catalysts via the esterification reaction. However, this process faces some serious and unavoidable problems such as side reactions, corrosion of equipment, and tedious isolation of catalyst and product. To overcome these limitations of corrosive homogeneous catalysts, many attempts have been made using solid acid catalysts and other alternatives, such as heteropolyacids (HPA), ${ }^{27}$ molecular sieves, ${ }^{28}$ and resins, by several scientists. ${ }^{29,30}$ Tao et $\mathrm{al}^{31}$ studied the reaction kinetics using BAIL, whereas Gangadwala et $a l .{ }^{30}$ proposed the kinetic expression. All these solid acid catalysts have exhibited good catalytic performance and have been extensively used in

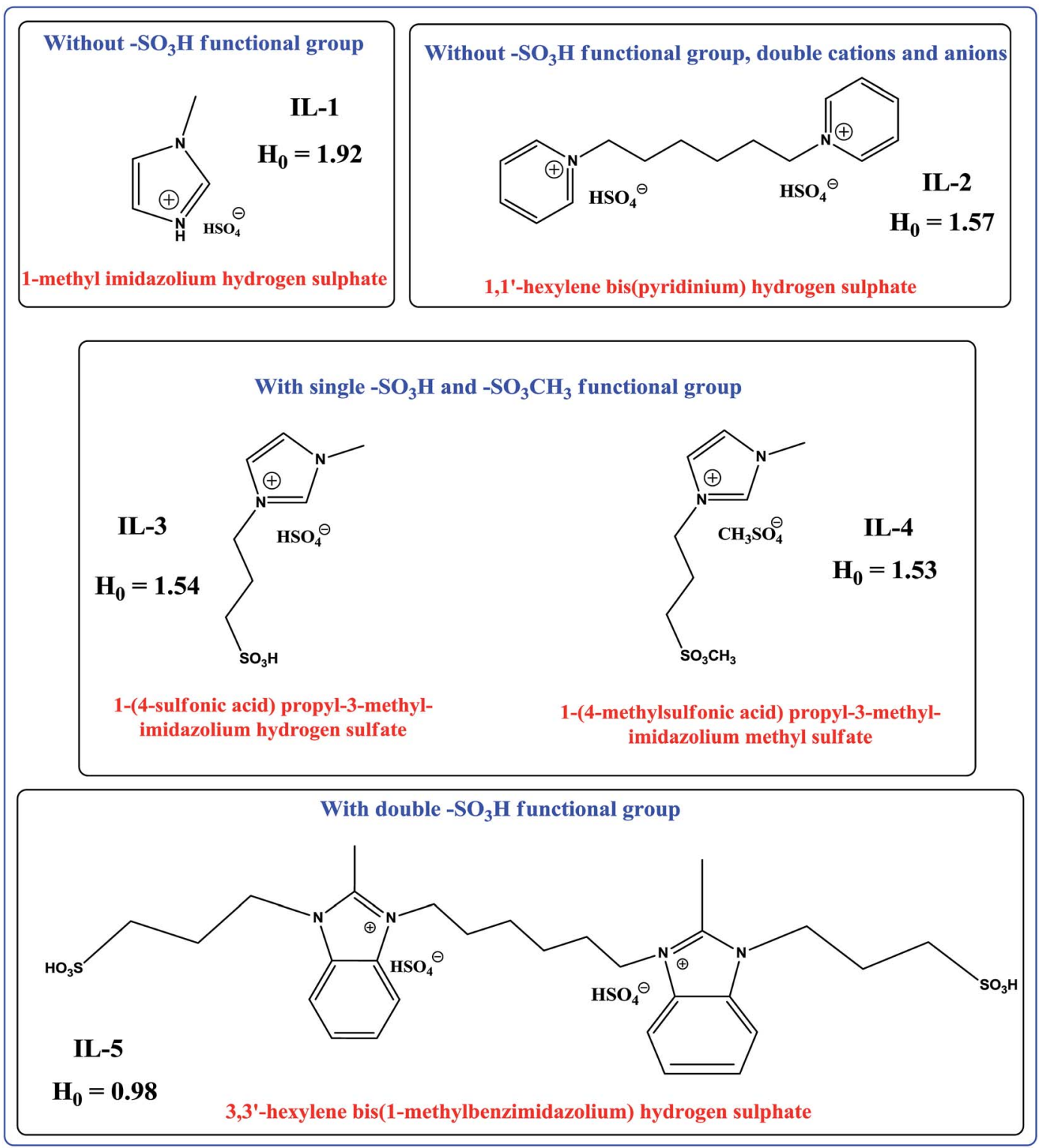

Scheme 2 Structures and acidities of the synthesized BAILs. 


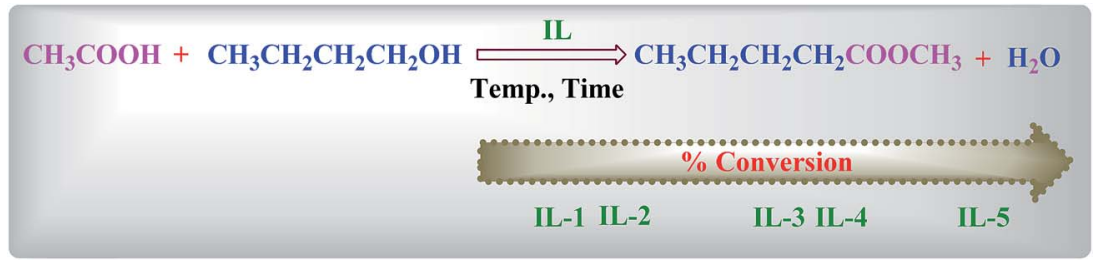

Scheme 3 Representative esterification reaction of acetic acid with $n$-butanol catalyzed by BAILs.

the industrial processes. However, for the catalytic distillation process, the esterification reaction takes place in a reactive distillation column. In particular, the most significant part of the use of BAIL in the esterification reactions is the acidity of BAIL, which is related to the structure of the IL and can be measured by $H_{0}$, directly affecting the conversion. Several examples of BAILs having diverse structures and their respective acidities are given in Scheme 1 and some of these have already been utilized in the esterification reactions. Considering this perspective of the ILs structure and acidity relationship, our study aimed at finding a better BAIL for the esterification reaction of $n$-butanol with acetic acid. Herein, we report the synthesis (Scheme 2) and characterization of halogen free BAILs. Among these, IL-5 was demonstrated to be a very efficient and reusable catalyst system for esterification. The IL could be a potential substitute for the predominant esterification catalytic systems for the following reasons: (a) IL-5 exhibited superior catalytic activity to that of the previously reported systems as well as to that of the other four ILs reported in our study, (b) the synthesis and purification processes are simple, easy to handle, and reproducible. Therefore, we have chosen IL-5 for further detailed studies, such as effects of catalyst loading, temperature, and reaction time. The results of the investigation validated many advantages of IL as a catalyst, such as mild reaction conditions, short reaction time, and higher conversion rate. The representative esterification reaction between acetic acid and $n$-butanol catalyzed by BAILs is given in Scheme 3 .

\section{Experimental}

\subsection{Materials and methods}

$N$-Methylimidazole, 2-methylbenzimidazole, pyridine, 1,6-dibromohexane, 1,3-propane sultone, and dimethyl sulfate (all these reagents with $>99 \%$ purity) were purchased from Sigma Aldrich and used as received. Sulfuric acid $\left(\mathrm{H}_{2} \mathrm{SO}_{4}\right)$ and other reagents, such as $n$-butanol and acetic acid, were obtained from commercially available sources and used without further purification. The ${ }^{1} \mathrm{H}$ and ${ }^{13} \mathrm{C}$ NMR spectra were obtained in $\mathrm{D}_{2} \mathrm{O}$ solvent using a Bruker AVANCE III $400 \mathrm{MHz}$ NMR Spectrometer with TMS as the internal standard. FT-IR spectra were obtained in the range $4000-500 \mathrm{~cm}^{-1}$ using a SHIMADZU IR Prestige-21 Spectrometer Fourier Transform Infrared Analyzer. Mass spectra were obtained using a Thermo Fisher Exactive Plus High Resolution Mass Spectrometer. Thermogravimetric and differential thermal analyses (TG-DTA) were carried out using a Setsys Evolution of France Setram instrument with a $\mathrm{N}_{2}$ flow and heating rate of $5{ }^{\circ} \mathrm{C} \mathrm{min}^{-1}$ from room temperature to $800{ }^{\circ} \mathrm{C}$.

\subsection{Synthesis of ILs}

2.2.1 IL-1 ([HMIM] $\left.\mathrm{HSO}_{4}\right)$. $N$-Methylimidazole $(5.0 \mathrm{~g}, 0.060$ $\mathrm{mol})$ and acetonitrile $(10 \mathrm{~mL})$ were charged in a round bottom flask, and the mixture was allowed to stir for $5 \mathrm{~min}$ at $0{ }^{\circ} \mathrm{C}$. Then, a stoichiometric amount $(5.97 \mathrm{~g}, 0.060 \mathrm{~mol})$ of conc. $\mathrm{H}_{2} \mathrm{SO}_{4}$ was added drop wise and the mixture was stirred for $1 \mathrm{~h}$ at $0{ }^{\circ} \mathrm{C}$. Then, stirring was continued for further $1 \mathrm{~h}$ at room temperature. The IL formed was repeatedly washed with ethyl acetate/ether to remove the unreacted material under reduced pressure and dried under high vacuum at $80{ }^{\circ} \mathrm{C}$ for $24 \mathrm{~h}^{17,33,34}$ Finally, the IL viscous oil ([HMIM] $\mathrm{HSO}_{4}$ ) was kept in a sealed tube under an argon atmosphere.

2.2.2 IL-2 ([HbPy] $\left.\mathrm{HSO}_{4}\right)$. Pyridine $(5.0 \mathrm{~g}, 0.063 \mathrm{~mol})$ and acetonitrile $(10 \mathrm{~mL})$ were charged in a round bottom flask, and the mixture was allowed to stir for $5 \mathrm{~min}$ at RT. Then, the solution of 1,6-dibromohexane ( $7.72 \mathrm{~g}, 0.031 \mathrm{~mol})$ in acetonitrile was added drop wise. The reaction was allowed to stir for $4 \mathrm{~h}$ at $95{ }^{\circ} \mathrm{C}$. White precipitation was formed, which was then cooled down to RT, washed with ether, and dried to obtain the solid white powder, which was vacuum dried at $100{ }^{\circ} \mathrm{C}$. Then, a stoichiometric amount $(6.19 \mathrm{~g}, 0.063 \mathrm{~mol})$ of conc. $\mathrm{H}_{2} \mathrm{SO}_{4}$ was added drop wise and the mixture was stirred at $0{ }^{\circ} \mathrm{C}$. Stirring was then continued for further $8 \mathrm{~h}$ under reflux conditions. The IL formed was repeatedly washed with ethyl acetate/ether to remove the unreacted material under reduced pressure and dried under high vacuum at $80{ }^{\circ} \mathrm{C}$ for $24 \mathrm{~h}^{.7,33,34}$

2.2.3 IL-3 ([MIM-PS] $\mathrm{HSO}_{4}$ ) and IL-4 ([MIM-PS] $\mathrm{CH}_{3} \mathrm{SO}_{4}$ ). $\mathrm{N}$ Methylimidazole $(5.0 \mathrm{~g}, 0.060 \mathrm{~mol})$ was dissolved in toluene, and to it, a solution of 1,3-propane sultone $(7.43 \mathrm{~g}, 0.060 \mathrm{~mol})$ in toluene was added with stirring in a round bottom flask at $0{ }^{\circ} \mathrm{C}$. After the addition was finished, the reaction was allowed to stir at RT for $24 \mathrm{~h}$. The resultant white colored mass was filtered out, washed with toluene, and then with diethyl ether, and vacuum dried at $100{ }^{\circ} \mathrm{C}$. To this white colored mass $(10.0 \mathrm{~g}, 0.049 \mathrm{~mol})$ (for zwitterion mass), a stoichiometric amount ( $4.80 \mathrm{~g}, 0.049 \mathrm{~mol})$ of conc. $\mathrm{H}_{2} \mathrm{SO}_{4} /$ dimethyl sulfate (DMS) $(6.17 \mathrm{~g}, 0.049 \mathrm{~mol})$ was added drop wise and the mixture was stirred for $6 \mathrm{~h}$ at $40{ }^{\circ} \mathrm{C}$. The IL formed was repeatedly washed with ethyl acetate/ether to remove the unreacted material under reduced pressure and dried under high vacuum at $80{ }^{\circ} \mathrm{C}$ for $24 \mathrm{~h}^{17,33,34}$ Finally, the ILs, ([MIM-PS] $\mathrm{HSO}_{4}$ ) and ([MIM-PS] $\mathrm{CH}_{3} \mathrm{SO}_{4}$ ), in the viscous oil form were kept in a sealed tube under an argon atmosphere.

2.2.4 IL-5 ([HbMBIM-PS] $\mathbf{H S O}_{4}$ ). 2-Methylbenzimidazole ( $4.0 \mathrm{~g}, 0.030 \mathrm{~mol})$, 1,6-dibromohexane $(3.7 \mathrm{~g}, 0.015 \mathrm{~mol})$, and acetonitrile $(10 \mathrm{~mL})$ were charged in a round bottom flask, and the mixture was allowed to stir for $48 \mathrm{~h}$ at $95{ }^{\circ} \mathrm{C}$. After the 
completion of reaction, the resultant brown colored solid mass was filtered out, washed twice with diethyl ether, and vacuum dried to obtain product-A. The product-A (5.2 g, $0.01 \mathrm{~mol})$ was dissolved in toluene and stirred. Then, a solution of 1,3-propane sultone $(2.5 \mathrm{~g}, 0.02 \mathrm{~mol})$ in toluene was added while stirring in an ice bath with the temperature maintained at $0-5{ }^{\circ} \mathrm{C}$. After the addition was finished, the reaction was allowed to stir at room temperature for $24 \mathrm{~h}$. The resultant sticky mass was separated out from the solvent and washed with toluene, then with diethyl ether, and vacuum dried at $100{ }^{\circ} \mathrm{C}$ to obtain product- $\mathrm{B}$. To this product $(10.0 \mathrm{~g}, 0.017 \mathrm{~mol})$, for a zwitterionic mass, a stoichiometric amount $(3.32 \mathrm{~g}, 0.034 \mathrm{~mol})$ of conc. $\mathrm{H}_{2} \mathrm{SO}_{4}$ was added and stirred for $6 \mathrm{~h}$ at $40{ }^{\circ} \mathrm{C}$. After the completion of the reaction, the IL formed was repeatedly washed with ethyl acetate/ether to remove the unreacted material under reduced pressure and dried under high vacuum at $80{ }^{\circ} \mathrm{C}$ for 24 h. ${ }^{17,33,34}$ Finally, the IL, ([HbMBIM-PS] $\mathrm{HSO}_{4}$ ), in the viscous oil form was kept in a sealed tube under an argon atmosphere.

\subsection{Characterization of the ILs}

2.3.1 IL-1 [HMIM] $\mathrm{HSO}_{4} \cdot{ }^{1} \mathrm{H}$ NMR $\left(\mathrm{D}_{2} \mathrm{O}, \delta / \mathrm{ppm}\right.$ relative to $\mathrm{TMS})=3 \mathrm{H}\left(-\mathrm{NCH}_{3}\right), 2 \mathrm{H}(-\mathrm{CH}$ aromatic protons $)$, and $1 \mathrm{H}$ $(-\mathrm{NCHN}) \cdot{ }^{13} \mathrm{C} \mathrm{NMR}\left(\mathrm{D}_{2} \mathrm{O} \delta / \mathrm{ppm}\right)=35\left(-\mathrm{NCH}_{3}\right), 119(-\mathrm{CH}), 121$ $(-\mathrm{CH})$, and $135(-\mathrm{NCHN})$. IR $(\mathrm{KBr})\left(\nu \mathrm{cm}^{-1}\right)=750(\mathrm{C}-\mathrm{H}$ stretching), 851 (aromatic $\mathrm{C}-\mathrm{H}$ bending), 1042 ( $\mathrm{S}=\mathrm{O}$ stretching), 1177 (C-N stretching), 1466 (C-C aromatic multiple bond stretching), 3147 (aromatic stretching), and $3450(\mathrm{~N}-\mathrm{H}$ stretching). The mass spectrum of the IL showed the correct molecular ion peak at mass $=m / z(+)$ 83.06. The TG-DTA result shows the thermal stability of the IL (Fig. S1(a)-(e) $\dagger$ ).

2.3.2 IL-2 [HbPy] $\mathrm{HSO}_{4} \cdot{ }^{1} \mathrm{H}$ NMR $\left(\mathrm{D}_{2} \mathrm{O}, \delta / \mathrm{ppm}\right.$ relative to $\mathrm{TMS})=4 \mathrm{H}\left(-\mathrm{CH}_{2}-\right), 4 \mathrm{H}\left(-\mathrm{CH}_{2}-\right), 4 \mathrm{H}\left(-\mathrm{NCH}_{2}-\right), 4 \mathrm{H}(-\mathrm{CH}$ aromatic protons), $2 \mathrm{H}$ (-CH- aromatic protons), and $4 \mathrm{H}(-\mathrm{CH}$ aromatic protons). ${ }^{13} \mathrm{C} \mathrm{NMR}\left(\mathrm{D}_{2} \mathrm{O} \delta / \mathrm{ppm}\right)=22.5\left(-\mathrm{CH}_{2}-\right.$ two times), 27.5 ( $-\mathrm{CH}_{2}-$ two times), $60\left(-\mathrm{NCH}_{2}-\right.$ two times), 127 (-CH- aromatic, four times), 142 ( $-\mathrm{CH}$ - aromatic, three times), and $144\left(-\mathrm{CH}-\right.$ aromatic, three times). IR $(\mathrm{KBr})\left(\nu \mathrm{cm}^{-1}\right)=764$ (C-H stretching), 851 (aromatic $\mathrm{C}-\mathrm{H}$ bending), 1030 ( $\mathrm{S}=\mathrm{O}$ stretching), 1169 (C-N stretching), 1435 (C-C aromatic multiple bond stretching), 1570 (for amine salts, N-H bending), 1770 (N$\mathrm{H}$ bending), 2981 (alkane $\mathrm{C}-\mathrm{H}$ stretching), 3147 (aromatic stretching), and 3450 (N-H stretching). The mass spectrum of the IL showed the correct molecular ion peak at mass $=m / z(+)$ 339.13. The TG-DTA result shows the thermal stability of the IL (Fig. S2(a)-(e)†).

2.3.3 IL-3 [MIM-PS] $\mathrm{HSO}_{4} \cdot{ }^{1} \mathrm{H}$ NMR $\left(\mathrm{D}_{2} \mathrm{O}, \delta / \mathrm{ppm}\right.$ relative to $\mathrm{TMS})=2 \mathrm{H}\left(-\mathrm{CH}_{2}-\right), 2 \mathrm{H}\left(-\mathrm{CH}_{2}-\right), 1 \mathrm{H}\left(-\mathrm{SO}_{3} \mathrm{H}\right), 3 \mathrm{H}\left(-\mathrm{CH}_{3}\right), 2 \mathrm{H}$ $\left(-\mathrm{NCH}_{2}-\right), 2 \mathrm{H}\left(-\mathrm{CH}-\right.$ aromatic protons), and $1 \mathrm{H}(-\mathrm{NCHN}) \cdot{ }^{13} \mathrm{C}$ $\mathrm{NMR}\left(\mathrm{D}_{2} \mathrm{O} \delta / \mathrm{ppm}\right)=25\left(-\mathrm{CH}_{2}-\right), 35.3\left(-\mathrm{NCH}_{3}\right), 47.4\left(-\mathrm{CH}_{2}-\right.$ $\left.\mathrm{SO}_{3} \mathrm{H}\right), 47.5\left(-\mathrm{NCH}_{2}-\right), 122$ (-CH- aromatic carbon), $124(-\mathrm{CH}-$ aromatic carbon), and 137 (-NCHN- aromatic carbon). IR ( $\mathrm{KBr})$ $\left(\nu \mathrm{cm}^{-1}\right)=748$ (C-H stretching), 904 (aromatic $\mathrm{C}-\mathrm{H}$ bending), 1027 ( $\mathrm{S}=\mathrm{O}$ stretching), 1161 (C-N stretching), 1461 (C-C aromatic multiple bond stretching), 1573 (for amine salts, $\mathrm{N}-\mathrm{H}$ bending), 1707 ( $\mathrm{N}-\mathrm{H}$ bending), 2949 (alkane $\mathrm{C}-\mathrm{H}$ stretching), 3091 (aromatic stretching), and 3114 ( $\mathrm{N}-\mathrm{H}$ stretching). Mass = $m / z(+)$ 164.98. The TG-DTA result shows the thermal stability of the IL (Fig. S3(a)-(e)†).

2.3.4 IL-4 [MIM-PS] $\mathrm{CH}_{3} \mathrm{SO}_{4} \cdot{ }^{1} \mathrm{H}$ NMR $\left(\mathrm{D}_{2} \mathrm{O}, \delta / \mathrm{ppm}\right.$ relative to $\mathrm{TMS})=3 \mathrm{H}\left(-\mathrm{CH}_{3}\right), 3 \mathrm{H}\left(\mathrm{CH}_{3}^{-}\right), 3 \mathrm{H}\left(-\mathrm{CH}_{3}\right), 4 \mathrm{H}\left(-\mathrm{CH}_{2}-\mathrm{CH}_{2}-\right.$ $\left.\mathrm{SO}_{3}\right), 2 \mathrm{H}\left(-\mathrm{NCH}_{2}-\right), 2 \mathrm{H}$ (-CH- aromatic protons), $2 \mathrm{H}(-\mathrm{CH}$ aromatic protons), and $1 \mathrm{H}(-\mathrm{NCHN}) .{ }^{13} \mathrm{C} \mathrm{NMR}\left(\mathrm{D}_{2} \mathrm{O} \delta / \mathrm{ppm}\right)=$ $24\left(-\mathrm{CH}_{2}-\right), 32.5\left(-\mathrm{NCH}_{3}\right), 45\left(-\mathrm{CH}_{2}-\mathrm{SO}_{3} \mathrm{H}\right), 47.5\left(-\mathrm{NCH}_{2}-\right), 112$ (-CH- aromatic carbon), 127 (- $\mathrm{CH}-$ aromatic carbon), 132 (-CH- aromatic carbon), 133 (-CH- aromatic carbon), and 141 $\left(-\mathrm{NCHN}-\right.$ aromatic carbon). IR $(\mathrm{KBr})\left(\nu \mathrm{cm}^{-1}\right)=750(\mathrm{C}-\mathrm{H}$ stretching), 850 (aromatic $\mathrm{C}-\mathrm{H}$ bending), 1032 ( $-\mathrm{S}=\mathrm{O}$ stretching), 1168 (C-N stretching), 1459 (C-C aromatic multiple bond stretching), 1575 (for amine salts, N-H bending), 1708 (N-H bending), 2951 (alkane $\mathrm{C}-\mathrm{H}$ stretching), 3082 (aromatic stretching), and 3270 (N-H stretching). Mass $=m / z(+)$ 269.09, $m / z(-)$ 96.04. The TG-DTA result shows the thermal stability of the IL (Fig. S4(a)-(e)†).

2.3.5 IL-5 [HbMBIM-PS] $\mathrm{HSO}_{4} \cdot{ }^{1} \mathrm{H}$ NMR $\left(\mathrm{D}_{2} \mathrm{O}, \delta / \mathrm{ppm}\right.$ relative to TMS $)=4 \mathrm{H}\left(-\mathrm{CH}_{2}-\right.$ of hexyl chain $\left.\times 2\right), 4 \mathrm{H}\left(-\mathrm{CH}_{2}-\right.$ of hexyl chain $\times 2), 2 \mathrm{H}\left(-\mathrm{SO}_{3} \mathrm{H} \times 2\right), 4 \mathrm{H}\left(-\mathrm{CH}_{2}-\right.$ of propane sultone chain $\times 2), 6 \mathrm{H}\left(-\mathrm{CH}_{3} \times 2\right), 4 \mathrm{H}\left(-\mathrm{CH}_{2}-\right.$ of $\left.-\mathrm{CH}_{2}-\mathrm{SO}_{3} \times 2\right), 4 \mathrm{H}$ $\left(-\mathrm{NCH}_{2}-\times 2\right), 4 \mathrm{H}\left(-\mathrm{NCH}_{2}-\times 2\right), 4 \mathrm{H}(-\mathrm{CH}-$ aromatic protons of the benzimidazole ring), and $4 \mathrm{H}(-\mathrm{CH}$ - aromatic protons of the benzimidazole ring). ${ }^{13} \mathrm{C} \mathrm{NMR}\left(\mathrm{D}_{2} \mathrm{O} \delta / \mathrm{ppm}\right)=12\left(-\mathrm{CH}_{3}\right), 24$ $\left(-\mathrm{CH}_{2}{ }^{-}\right), 25\left(-\mathrm{CH}_{2}-\right), 28\left(-\mathrm{CH}_{2}-\right), 33\left(-\mathrm{NCH}_{2}-\right), 45\left(-\mathrm{NCH}_{2}{ }^{-}\right), 48$ $\left(-\mathrm{NCH}_{2}-\right), 50\left(-\mathrm{NCH}_{2}-\right), 113(-\mathrm{CH}-$ aromatic $), 125(-\mathrm{CH}-$ aromatic), 132 (-NCH- aromatic), and 150 (-NCHN- aromatic). IR (KBr) $\left(\nu \mathrm{cm}^{-1}\right)=777$ (C-H stretching), 1036 (O-H bending), 1195 (C-N stretching), 1449 (C-C aromatic multiple bond stretching), 1641 (aromatic $\mathrm{C}=\mathrm{N} \& \mathrm{C}=\mathrm{C}$ stretching), 2923 (alkane C-H stretching), 3082 (aromatic stretching), and 3414 (N-H stretching). The mass spectrum of the IL showed the correct molecular ion peak at mass $=m / z(+)$ 785.33. The TGDTA result shows the thermal stability of the IL (Fig. S5(a)-(e)†).

\subsection{UV-vis acidity evaluation}

Solutions of the ILs were prepared in deionized water (dried under vacuum at $80{ }^{\circ} \mathrm{C}$ for $2 \mathrm{~h}$ ). All spectra were obtained using an Agilent B453 spectrophotometer.

\subsection{Apparatus and procedure for esterification}

The schematic of the apparatus is shown in Scheme S1. $\dagger$ The esterification reactions were carried out in a $100 \mathrm{~mL}$ roundbottom flask with a reflux condenser immersed in a constant temperature oil bath to maintain the required reaction temperature. In a typical run, acetic acid $(0.25 \mathrm{~mol})$ and $n$ butanol $(0.25 \mathrm{~mol})$ were charged into the flask. When the temperature was increased to the desired value, the IL catalyst was added to the flask. Samples were collected from the reaction mass at regular intervals to monitor the progress of the reaction, and when the reaction was completed, the solution became biphasic. The upper layer containing the desired ester product could be separated by simple decantation, whereas the bottom layer containing the IL can be reused after the removal of water, butyl acetate residues, and unreacted reactants, 
including acetic acid and $n$-butanol, via rotary evaporation and subsequent drying under vacuum for $24 \mathrm{~h}$.

The upper layer was analyzed by GC using $\mathrm{N}_{2}$ as the carrier gas in an HP 6890 GC analyzer (Agilent) equipped with an FID detector and a capillary column HP-5 $(50 \mathrm{~m} \times 0.32 \mathrm{~mm} \times 0.25$ $\mu \mathrm{m})$. The temperature of the inlet and the detector was kept at $200{ }^{\circ} \mathrm{C}$. The results obtained via GC were also confirmed from the independent titrations using the standard sodium hydroxide $\left(0.25 \mathrm{~mol} \mathrm{~L}^{-1} \mathrm{NaOH}\right)$ solution. The reliability of the titration method was confirmed via the analysis of the standard samples containing $n$-butyl acetate to ensure that the hydrolysis of esters does not take place during the course of titration. The analytical uncertainty of GC was less than $2 \%$, which is well within the acceptable limits.

\section{Results and discussion}

All these ILs were obtained in high yields of $>97 \%$. These dissolve well in polar solvents, such as water, methanol, ethanol, DMF, and DMSO, whereas are insoluble in weakly polar solvents, such as ether, toluene, hexane, ethyl acetate, cyclohexane, tetrahydrofuran, and 1,4-dioxane.

\subsection{Determination of the $\boldsymbol{H}_{0}$ values of BAILs}

The measurement of the acidic scale of these Brönsted acidic ILs was conducted using an Agilent 8453 UV-vis spectrophotometer with a basic indicator, according to the previously reported studies. ${ }^{35,36}$ With the increase of the acidic scale of the acidic ILs, the absorbance of the unprotonated form of the basic indicator decreased, whereas the protonated form of the indicator could not be observed because of its small molar absorptivity and location; hence, the $[\mathrm{I}] /\left[\mathrm{IH}^{+}\right]$(I represents indicator) ratio could be calculated from the maximum absorbance value according to the Lambert-Beer law. The differences in the absorbance after the addition of Brönsted acidic ILs were determined, and then the Hammett function, $H_{0}$, was calculated using eqn (1). This value could be regarded as the relative acidity of the ILs;

$$
H_{0}=\mathrm{pK}(\mathrm{I})_{\mathrm{aq}}+\log \left([\mathrm{I}] /\left[\mathrm{IH}^{+}\right]\right)
$$

With the same concentration of 4-nitroaniline $\left(10 \mathrm{mg} \mathrm{L}^{-1}\right.$, $\left.\mathrm{pK}(\mathrm{I})_{\mathrm{aq}}=0.99\right)$ and ILs $\left(5 \mathrm{mmol} \mathrm{L}^{-1}\right)$ in deionized water, we determined the $H_{0}$ values of the Brönsted acidic ILs. The maximum absorbance of the unprotonated form of the indicator was observed at $378 \mathrm{~nm}$ in water. When an acidic IL was added, the absorbance of the unprotonated form of the indicator decreased. As shown in Fig. 1, the absorbance of the unprotonated form of the indicator on the acidic ILs decreased as follows: IL-5 > IL-4 > IL-3 > IL-2 > IL-1. The results are presented in Table 1 . A lower $H_{0}$ value indicates a stronger acidity of the IL. Due to the presence of two $-\mathrm{SO}_{3} \mathrm{H}$ groups and two $\mathrm{HSO}_{4}{ }^{-}$groups, IL-5 becomes the most acidic, whereas since IL-1 contains only one $\mathrm{HSO}_{4}{ }^{-}$group and no $\mathrm{SO}_{3} \mathrm{H}$ group, it is the least acidic catalyst. The higher the acidity of the catalyst, the higher the electrophilic character of the $\mathrm{C}$ atom of the $-\mathrm{COOH}$ group, and the better the esterification reaction. Hence, IL-5 showed the best catalytic performance.

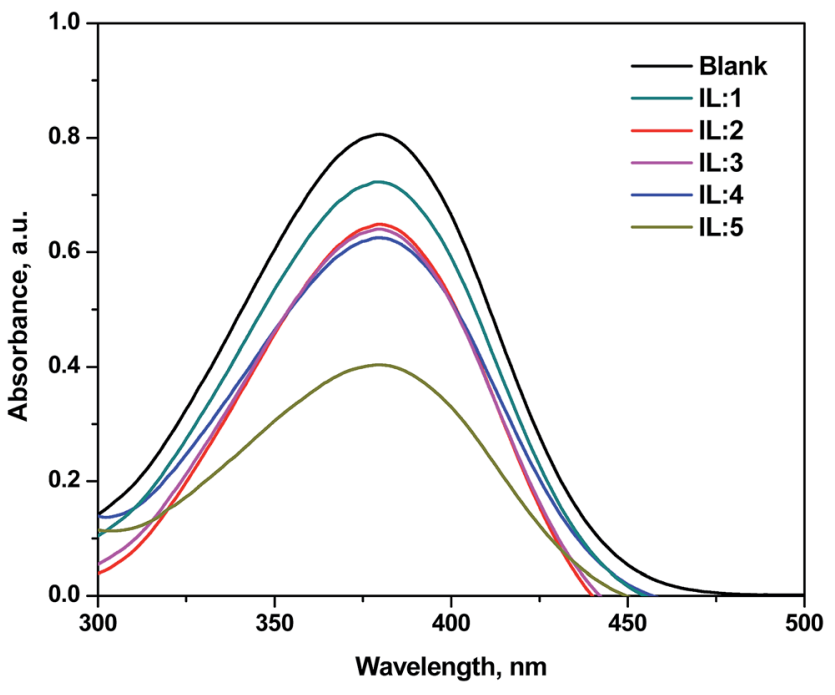

Fig. 1 UV-vis absorbance spectra of 4-nitroaniline with and without the addition of BAILs $\left(5 \mathrm{mmol} \mathrm{L}^{-1}\right)$ in water.

Ultimately, we obtained the acidity order of the ILs with the following $H_{0}$ values (Table 1): IL-5 (0.98) > IL-4 (1.53) > IL-3 (1.54) $>$ IL-2 (1.57) > IL-1 (1.92), suggesting that the Brönsted acidity of IL-5 was the relatively strongest amongst the ILs used in this study. The acidity of the ILs depends on the characteristics of both cation and anion. When the cationic part of the ILs was same, the acidity of the ILs significantly depended on the anionic part. In this study, we described the results of our investigation to identify the novel and more efficient IL catalyst systems for the esterification of selective acetic acid and $n$-butanol to produce an ester. In our study, we focused on the BAILs with no $-\mathrm{SO}_{3} \mathrm{H}$, single $-\mathrm{SO}_{3} \mathrm{H}$, and double $-\mathrm{SO}_{3} \mathrm{H}$ groups attached to the cation and hydrogen and/or methyl sulphate anions. This class of taskspecific ILs (TSIL) was introduced by Cole et al. ${ }^{17}$ and has already been tested in several synthetic applications..$^{17,37-40}$

An IL is generally prepared to full acidic strength by mixing equimolar parts of the appropriate cations with anions. It is obvious that the Brönsted acidity of the ILs depends on the nature of the cations, anions, and attached alkyl functional groups. Soni et $a .^{41}$ reported the relationship between the structures of the IL and acidity. A similar phenomenon could be applied in the ILs studied herein. The absorbance trend observed for the ILs is: IL-5 > IL-4 > IL-3 > IL-2 > IL-1. IL-5 bearing two sulfonic acid groups on the cation has the strongest acidity, whereas IL-4 and IL-3 have the next strongest acidities than that of those bearing no such groups, suggesting the significant effect of the alkyl sulfonic acid group on the acidity of the IL. On the other hand, IL-2 and IL-1 have the least acidity compared to that of the other ILs and this is because of the dual acid character as the presence of a proton on nitrogen has a significant effect on the acidity along with the $\mathrm{HSO}_{4}{ }^{-}$anion (Scheme 2).

\subsection{The assessment of the catalytic performance}

All these synthesized ILs were employed as catalysts for the esterification reaction of $n$-butanol with acetic acid. The 
Table 1 Calculation and comparison of the $H_{0}$ values of BAILs in water at $30{ }^{\circ} \mathrm{C}$ using a 4-nitroaniline indicator. (ILs concentration: $5 \mathrm{mmol} \mathrm{L}^{-1}$ )

\begin{tabular}{llcccc}
\hline Entry & ILs & $A_{\max }$ & {$[\mathrm{I}](\%)$} & {$\left[\mathrm{IH}^{+}\right](\%)$} & $H_{0}$ \\
\hline 1 & No IL & 0.805 & 100.0 & 0 & - \\
2 & IL-1 & 0.720 & 89.44 & 10.45 & 1.92 \\
3 & IL-2 & 0.640 & 79.50 & 20.50 & 1.57 \\
4 & IL-3 & 0.630 & 78.27 & 21.73 & 1.54 \\
5 & IL-4 & 0.625 & 77.63 & 22.37 & 1.53 \\
6 & IL-5 & 0.401 & 49.81 & 50.19 & 0.98
\end{tabular}

representative esterification reaction catalyzed by ILs is outlined in Scheme 3. IL-5 was found to be the most active for the esterification reaction. For all these reactions, high conversion was obtained under the specified experimental conditions. It is well known that esterification is a reversible reaction and to complete the reaction, the water formed during the reaction must be simultaneously removed. Herein, water produced in the reaction slightly affects the acidity of the catalyst. Therefore, the change in the activation energy due to this factor is very low and almost negligible. An outstanding feature of these synthesized ILs is that they exhibit excellent solubility in water, but are hardly miscible with esters; therefore, water formed during the reaction can easily enter into the IL phase from the produced ester. This induces a spontaneous phase separation, which may drive the reaction towards completion. ${ }^{33}$

The esterification of acetic acid with $n$-butanol in the presence of various ILs as catalysts was performed for testing the reaction kinetics at $80^{\circ} \mathrm{C}$, with an equal molar ratio of acid to alcohol and catalyst loading of $25 \% \mathrm{w} / \mathrm{w}$ (based on the mass of acetic acid). It is shown in Fig. 2 that IL catalysts exhibit different catalytic activities. Slight improvements in the conversion can be considered due to the length of the alkyl chain, such as with propyl, where a slightly higher conversion can be achieved as compared to butyl, ${ }^{17}$ which is also supported by Ahmad et al. ${ }^{42}$ whereas acidity played the major role in the catalytic performance during the esterification reaction. Eventually, the conversion is according to the acidity, which can be measured by Hammett acidity. In a comparison of Hammett acidity values of ILs, it can be observed that two $-\mathrm{SO}_{3} \mathrm{H}$ groups have a higher $H_{0}$ value $(0.98)$ than that of one $-\mathrm{SO}_{3} \mathrm{H}$ (1.54) functional group.

From the acidity order of these ILs ranked by $H_{0}$ value (see Table 1), it is obvious that acidity has a great influence on the catalytic performance during the esterification reaction. ILs having stronger acidity demonstrated higher catalytic activities. From Fig. 2, the conversion of acetic acid is highest in the case of IL-5 catalyzed reaction as compared to that of those catalyzed by other ILs. IL-5 shows more efficient catalytic performance than that of the remaining ILs because of the stronger acidity of the double $-\mathrm{SO}_{3} \mathrm{H}$ functional group with a hydrogen sulfate anion relative to the single $\mathrm{HSO}_{4}^{-}$anion or single $-\mathrm{SO}_{3} \mathrm{H}$ functional group. The IL-3 and IL-4 containing a propyl sulfonic acid can improve its Brönsted acidity in comparison to IL-1 and IL-2. However, in the case of IL-5, it has two propyl sulfonic acid groups with the $\mathrm{HSO}_{4}^{-}$anion; therefore, it can further improve acidity, and as a result, it has super strong acidity. This very strong

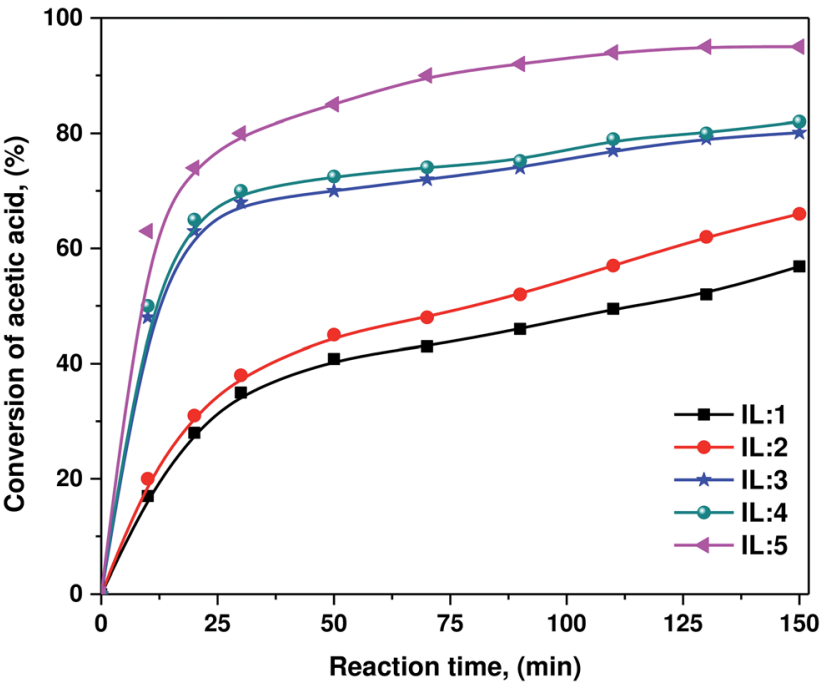

Fig. 2 Conversion of acetic acid into an ester with $n$-butanol as a function of reaction time using various ILs at $80^{\circ} \mathrm{C}$; (a) IL-1, (a) IL-2, (a) IL-3, (a) IL-4, and (a) IL-5.

acidity enables the IL-5 to have the highest catalytic activity, and this is in accordance with the general phenomena of acid catalysis for esterification.

3.2.1 Influence of temperature on the conversion of acetic acid. As discussed in earlier sections, time has an influence on the conversion of acetic acid in the presence of all ILs. In the case of IL-5, from 90 min onwards, it shows no marginal difference in the conversion. Therefore, we chose the $90 \mathrm{~min}$ as the optimal time to check the effect of temperature on the conversion using IL-5. Fig. 3 showed that temperature also has a great effect on the conversion of acetic acid. As we increase the temperature, the \% conversion of acetic acid increases.

A vital advantage of BAILs as esterification catalysts is that after the completion of reaction, when cooled down to room

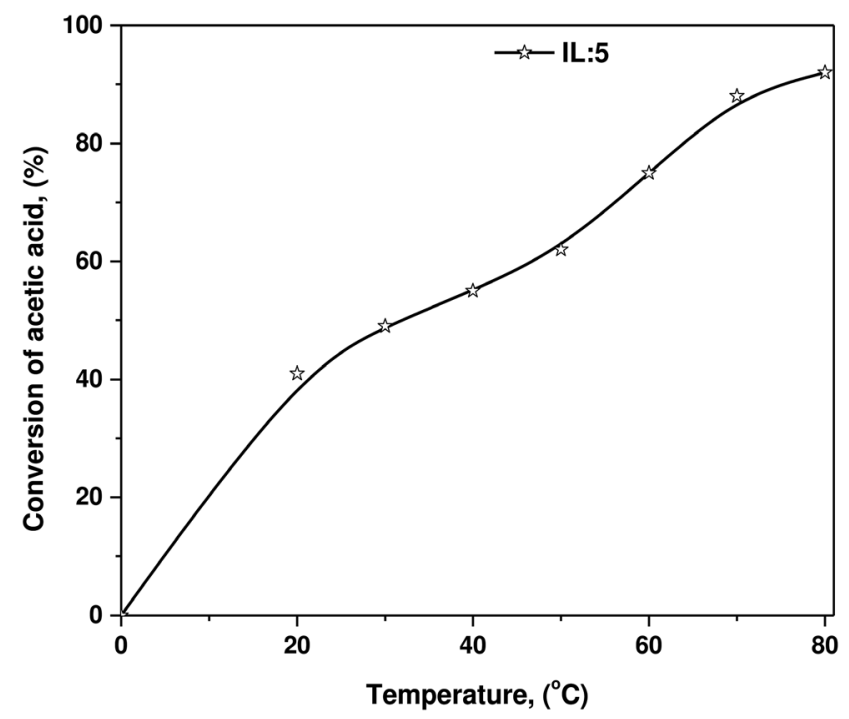

Fig. 3 Conversion of acetic acid into an ester with $n$-butanol as a function of reaction temperature using $\mathrm{IL}-5$ at 90 min reaction time. 
Table 2 Esterification of $n$-butanol with acetic acid catalyzed by different BAILs

\begin{tabular}{|c|c|c|c|c|c|c|}
\hline ILs & Catalyst loading (\%) & Temp. $\left({ }^{\circ} \mathrm{C}\right)$ & Time (h) & Conv. (\%) & Phase Sep. & Ref. \\
\hline $\mathrm{Hnmp}^{+} \mathrm{HSO}_{4}^{-}$ & 0.5 & 80 & 2 & 67 & $\mathrm{Y}$ & 43 \\
\hline $\mathrm{Hnmp}^{+} \mathrm{MeSO}_{3}{ }^{-}$ & 25 & RT & 4 & 95 & $\mathrm{Y}$ & 44 \\
\hline $\mathrm{H}$-pyridine ${ }^{+} \mathrm{HSO}_{4}^{-}$ & 25 & 85 & 2 & 71 & $\mathrm{Y}$ & 32 \\
\hline $\mathrm{Hmim}^{+} \mathrm{HSO}_{4}^{-}$ & 25 & 85 & 2 & 55 & $\mathrm{Y}$ & 31 \\
\hline $\mathrm{Et}_{3} \mathrm{NH}^{+} \mathrm{HSO}_{4}^{-}$ & 25 & 85 & 2 & 50 & $\mathrm{Y}$ & 31 \\
\hline IL-3 & 25 & 80 & 1.5 & 73.9 & $\mathrm{Y}$ & This work \\
\hline $\mathrm{IL}-4$ & 25 & 80 & 1.5 & 75 & $\mathrm{Y}$ & This work \\
\hline IL-5 & 25 & 80 & 1.5 & 93.2 & $\mathrm{Y}$ & This work \\
\hline
\end{tabular}

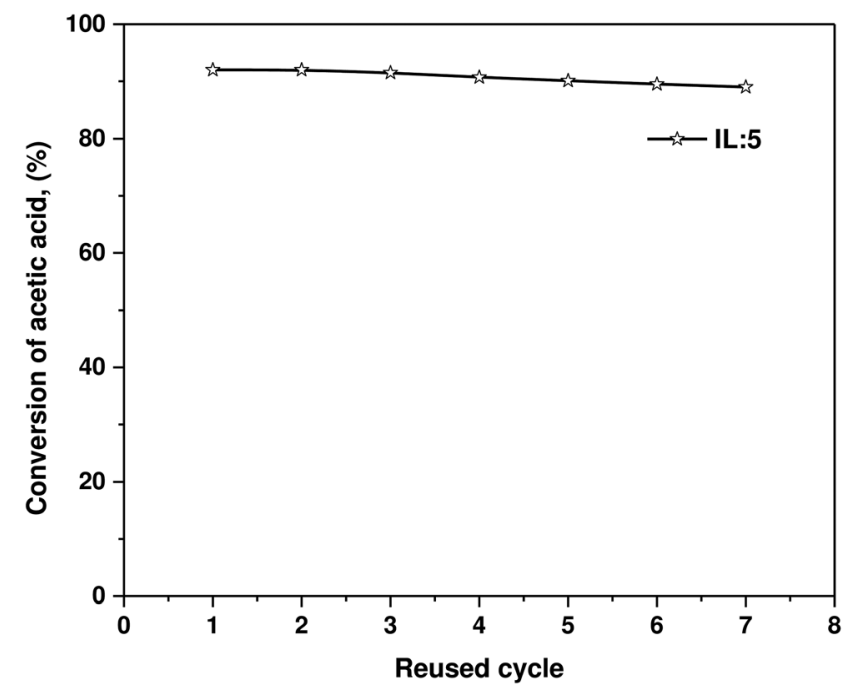

Fig. 4 Reusability study of IL-5 for the conversion of acetic acid in ester with $n$-butanol at $80{ }^{\circ} \mathrm{C}$ reaction temperature and $90 \mathrm{~min}$ reaction time. temperature, an organic phase consisting of the ester (butyl acetate) product is often found to be separated from the IL phase (Table 2). However, water removed from the reaction and the remaining reactants persist in the IL phase and the ester product can be isolated as a pure component. High conversion under usual equilibrium limited conditions is possible because of this phase separation (Fig. S6†).

Although high yields have been achieved with the BAIL catalysts, a lower esterification yield is equally common (Table 2). As a result, the catalytic reaction medium is potentially recyclable (Fig. 4).

The advantage of mild reaction conditions helps to justify the method on the grounds of green chemistry. However, not all the reactions can be performed at room temperature. To reduce the high catalyst loadings that are usually applied, an elevated temperature is required.

\subsection{Activation energy calculation for IL-5}

For a general reaction, $\mathrm{A}+\mathrm{B} \rightarrow \mathrm{C}+\mathrm{D}$, where $\mathrm{A}=$ acetic acid and $\mathrm{B}=n$-butanol, it can be written (assuming a first order reaction and ideal system) that

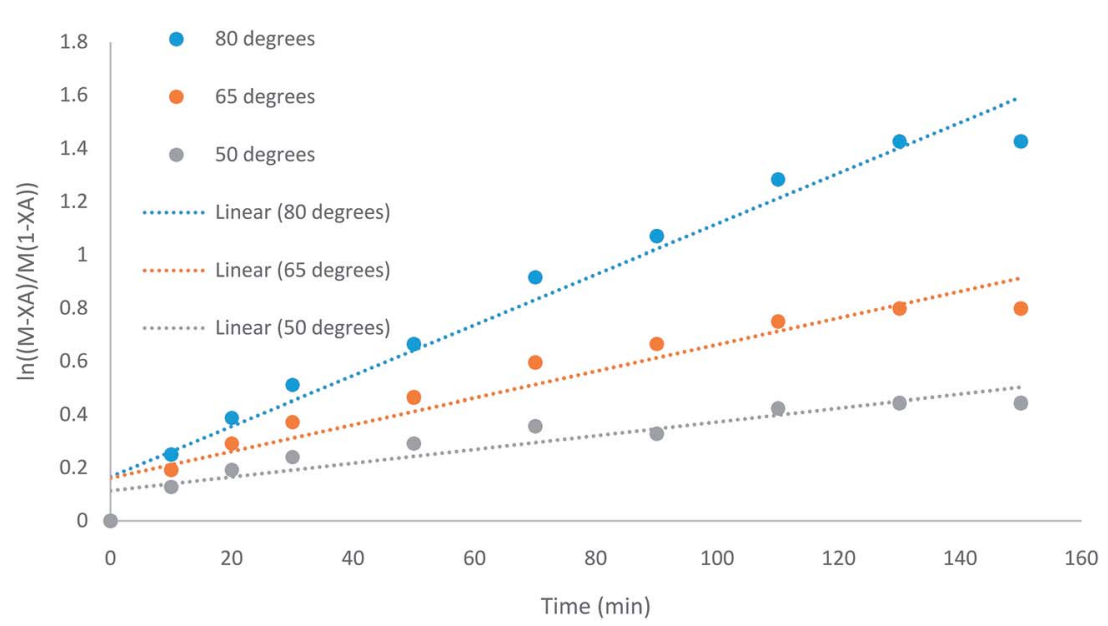

Fig. 5 Plot for the kinetic study of IL-5 at three different temperatures $\left(50^{\circ} \mathrm{C}, 65^{\circ} \mathrm{C}\right.$, and $80{ }^{\circ} \mathrm{C}$ ) in the time span ranging from 0 to 150 min. 


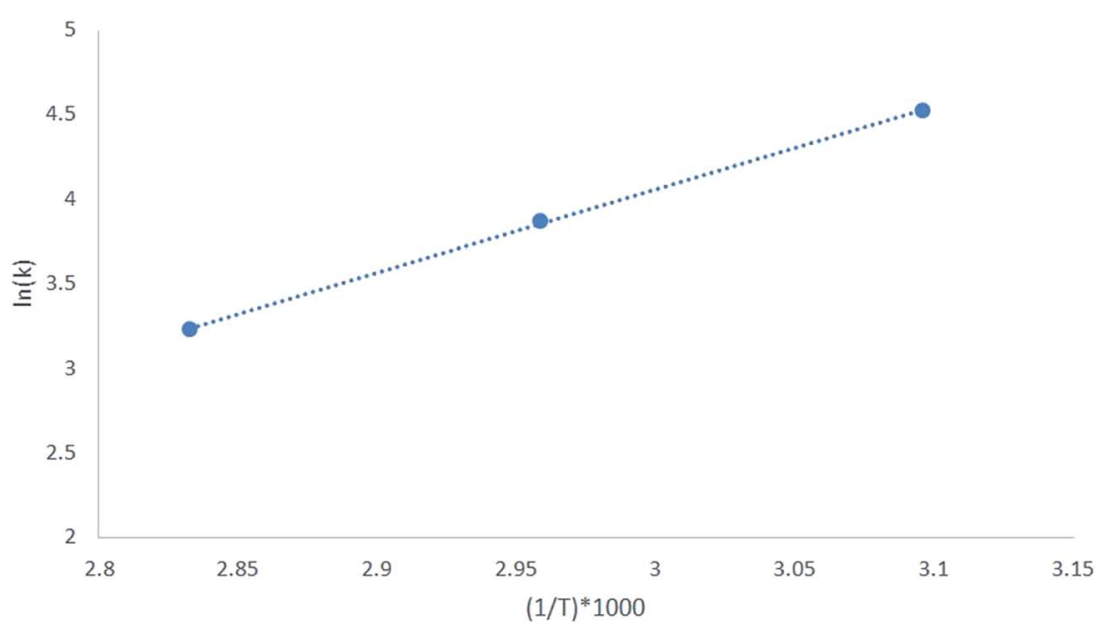

Fig. 6 Plot for the calculation of activation energy of IL-5, which suggests that the value of the activation energy is approximately $35 \mathrm{~kJ} \mathrm{~mol}^{-1}$.

$$
\ln \frac{M-X_{\mathrm{A}}}{M\left(1-X_{\mathrm{A}}\right)}=C_{\mathrm{A} 0}(M-1) k t
$$

where

$M=\frac{C_{\mathrm{B} 0}}{C_{\mathrm{A} 0}}=$ initial molar ratio of $n$-butanol and acetic acid, $X_{\mathrm{A}}=$ conversion of acetic acid at any particular time $t$ and temperature, $k=$ reaction rate constant (lit $\mathrm{mol}^{-1} \mathrm{~min}^{-1}$ ).

The kinetics of this particular system have been investigated by plotting $\ln \frac{M-X_{\mathrm{A}}}{M\left(1-X_{\mathrm{A}}\right)}$ with respect to time $(t)$ and the plot showed a linear trend (Fig. 5), which also proved that the assumption of a first order reaction was quite accurate. From this equation, it was clear that the slope of this straight line would be $C_{\mathrm{A} 0}(M-1) k \cdot{ }^{46,47}$ As both the initial concentration and ratio of the initial concentrations were known, the reaction rate constant $k$ was easily calculated. The same experiments were conducted at three different temperatures, such as $80^{\circ} \mathrm{C}, 65^{\circ} \mathrm{C}$, and $50{ }^{\circ} \mathrm{C}$. The Arrhenius equation is $k=A \mathrm{e}^{-\frac{E}{R T}}$. Therefore, plotting $\ln k$ with respect to $1 / T$ shows a linear curve, the slope of which is $\left(-\frac{E}{R}\right)$ and the activation energy was calculated from the slope (Fig. 6).$^{48}$ Intuitively, from the conversion rate of acetic acid, it is expected that IL-5 should have the lowest activation energy as the conversion rate is highest for this case. Thus, the activation energy was calculated for IL-5 and was found to be approximately $35 \mathrm{~kJ} \mathrm{~mol}^{-1}$; this activation energy value is quite lower than that of the other reported IL catalysts. ${ }^{49}$ Hence, it shows higher activity.

\section{Conclusions}

In summary, BAIL catalysts were synthesized in high yields of $>97 \%$. The catalysts are simple to produce, require only mild reaction conditions, are recyclable, and efficient in the catalysis of the esterification of acetic acid with $n$-butanol. The conversion of acetic acid can be effectively improved with the increase of reaction temperature or catalyst loading in the presence of
ILs; however, it would not be operational after reaching a certain point due to the limitation of the equilibrium of the chemical reaction. Higher conversion can be achieved by changing the acidity of the IL catalyst. The initial reaction rate is also found to linearly increase with the catalyst loading. Based on this observation, we concluded that the BAILs have potential to be used as catalysts for acid-promoted organic reactions, and some studies have already been reported on these ILs except for IL-5. Hence, it is anticipated that IL-5, which has the special feature of a double $-\mathrm{SO}_{3} \mathrm{H}$ functional group, could be employed for significant studies to explore its further scope as an IL catalyst.

\section{Authors contribution}

All authors equally contributed to this work.

\section{Conflict of interest}

The authors declare that there is no conflict of interest regarding this publication.

\section{Acknowledgements}

Dr RLV is grateful to Prof. S. S. Soni for his fruitful guidance in the synthesis and applications of ionic liquids.

\section{References}

1 R. C. Larock, Comprehensive Organic Transformations, John Wiley and Sons, Inc., New York, 1999.

2 D. C. Forbes and K. J. Weaver, J. Mol. Catal. A: Chem., 2004, 214, 129.

3 M. J. Earle and K. R. Seddon, Pure Appl. Chem., 2000, 72, 1391.

4 R. D. Rogers and K. R. Seddon, Science, 2003, 302, 792.

5 R. L. Vekariya, D. Ray, V. K. Aswal, P. A. Hassan and S. S. Soni, Colloids Surf., A, 2014, 462, 153. 
6 S. S. Soni, R. L. Vekariya and V. K. Aswal, RSC Adv., 2013, 3, 8398.

7 R. L. Vekariya, V. K. Aswal, P. A. Hassan and S. S. Soni, Langmuir, 2014, 30, 14406.

8 T. Welton, Chem. Rev., 1999, 99, 2071.

9 Ionic Liquids in Synthesis, ed. P. Wasserscheid and T. Welton, Wiley-VCH, Weinheim, 2003.

10 R. Sheldon, Chem. Commun., 2001, 2399.

11 J. G. Huddleston and R. D. Rogers, Chem. Commun., 1998, 16, 1765.

12 Y. Ito and T. Nohira, Electrochim. Acta, 2000, 45, 2611.

13 C. Chiappe and D. Pieraccini, J. Phys. Org. Chem., 2005, 18, 275.

14 H. O. Bourbigou and L. Magna, J. Mol. Catal. A: Chem., 2002, 182-183, 419.

15 N. V. Plechkova and K. R. Seddon, Chem. Soc. Rev., 2008, 37, 123.

16 D. Zhao, M. Wu, Y. Kou and E. Min, Catal. Today, 2002, 74, 157.

17 A. C. Cole, J. L. Jensen, I. Ntai, K. L. T. Tran, K. J. Weaver, D. C. Forbes and J. H. Davis, J. Am. Chem. Soc., 2002, 124, 5962.

18 F. Shi, Y. Q. Deng, T. L. Sima, J. J. Peng, Y. L. Gu and B. T. Qiao, Angew. Chem., Int. Ed., 2003, 42, 3257.

19 Y. Q. Deng, F. Shi, J. J. Beng and K. Qiao, J. Mol. Catal. A: Chem., 2001, 165, 33.

20 P. Vogel, Y. Lam, A. Simon and K. N. Houk, Catalysts, 2016, 6, 128.

21 M. H. Zhu, Z. J. Feng, X. M. Hua, H. L. Hu, S. L. Xia, N. Hu, Z. Yang, I. Kumakiri, X. S. Chen and H. Kita, Microporous Mesoporous Mater., 2016, 233, 171.

22 S. G. Lee and J. H. Park, J. Mol. Catal. A: Chem., 2003, 194, 49.

23 Z. Y. Duan, Y. L. Gu and Y. Q. Deng, J. Mol. Catal. A: Chem., 2006, 246, 70.

24 H. P. Zhu, F. Yang, J. Tang and M. Y. He, Green Chem., 2003, $5,38$.

25 J. Z. Gui, X. H. Cong, D. Liu, X. Zhang, Z. Hu and Z. Sun, Catal. Commun., 2004, 5, 473.

26 R. C. Larock, Comprehensive Organic Transformations, WileyVCH, New York, 1999.

27 J. Das and K. M. Parida, J. Mol. Catal. A: Chem., 2007, 264, 248.
28 B. R. Jermy and A. Pandurangan, J. Mol. Catal. A: Chem., 2005, 237, 146.

29 S. Steinigeweg and J. Gmehling, Ind. Eng. Chem. Res., 2002, 41, 5483.

30 J. Gangadwala, S. Mankar and S. Mahajani, Ind. Eng. Chem. Res., 2003, 42, 2146.

31 D. J. Tao, Y. T. Wu, Z. Zhou, J. Geng, X. B. Hu and Z. B. Zhang, Ind. Eng. Chem. Res., 2011, 50, 1989.

32 H. Zhou, J. Yang, L. Ye, H. Lin and Y. Yuan, Green Chem., 2010, 12, 661.

33 J. Liu, Z. Li, J. Chen and C. Xia, Catal. Commun., 2009, 10, 799.

34 J. Sun, H. Li, H. Song, Q. Wu, Y. Zhao and Q. Jiao, RSC Adv., 2015, 5, 87200.

35 R. Kore and R. Srivastava, J. Mol. Catal. A: Chem., 2011, 345, 117.

36 Y. Wang, D. Jiang and L. Dai, Catal. Commun., 2008, 9, 2475.

37 A. H. J. Akbari, H. R. Kalhor and S. A. Kohan, J. Comb. Chem., 2010, $12,137$.

38 S. Saravanamurugan and A. Riisager, Catal. Today, 2013, 200, 94.

39 H. R. Shaterian and A. Hosseinian, Res. Chem. Intermed., 2013, 1.

40 H. Ren, Y. Zhou and L. Liu, Bioresour. Technol., 2013, 129, 616.

41 D. A. Kotadia and S. S. Soni, Catal. Sci. Technol., 2013, 3, 469.

42 E. Ahmad, M. I. Alam, K. K. Pant and M. A. Haider, Green Chem., 2016, 18, 4804.

43 B. Zhou, Y. Fang, H. Gu, S. Zhang, B. Huang and K. Zhang, Front. Chem. Eng. China, 2009, 3, 211.

44 H. Zhang, F. Xu, X. Zhou, G. Zhang and C. Wang, Green Chem., 2007, 9, 1208.

45 D. J. Tao, X. M. Lu, J. F. Lu, K. Huang, Z. Zhou and Y. T. Wu, Chem. Eng. J., 2011, 171, 1333.

46 N. Calver, B. Gonzales and A. Dominguez, Chem. Eng. Process., 2007, 46, 1317.

47 W. T. Liu and C. S. Tan, Ind. Eng. Chem. Res., 2001, 40, 3281.

48 I. Kirbaslar, B. Baykal and U. Dramur, Turk. J. Eng. Environ. Sci., 2001, 25, 569.

49 V. Ragaini, C. L. Bianchi and C. Pirola, Chem. Eng. J., 2007, 131, 257. 